Brit. J. industr. Med., 1948, 5, 204.

\title{
THE EVALUATION OF SKIN CLEANSERS AND PROTECTIVE CREAMS FOR WORKMEN EXPOSED TO MINERAL OIL
}

\author{
BY \\ C. N. D. CRUICKSHANK \\ From the Industrial Medicine Research Unit (Medical Research Council), Birmingham Accident Hospital
}

(RECEIVED FOR PUBLICATION, APRIL 26, 1948)

\section{Introduction}

In many industrial processes the workman's skin is constantly exposed to mineral oils which are known to be potentially harmful. Adequate removal of these oils from the skin after work, though desirable, is not easily accomplished, and the use of abrasive and excessively alkaline cleansers for this purpose is a frequent cause of skin disease in industry. Various cleansing agents free from these defects have now been marketed. In order to facilitate cleansing and to protect the skin during work, " barrier " or protective creams are frequently used. In this paper methods are described of estimating the effectiveness of these agents. The experiments were carried out directly on the human skin, since it is believed that only by reproducing as accurately as possible the natural conditions of use of these substances can a reliable assessment of their efficiency be obtained.

\section{Evaluation of Cleansing Agents Principles of Method}

Fluorescence of Oils on the Skin.-Uncontaminated oils are invisible on the skin in small amounts, so that the effectiveness of their removal cannot be assessed by direct examination. This difficulty was overcome by utilizing the fact that most mineral oils produce a brilliant violet fluorescence when examined in ultra-violet light. This method of detecting the presence of mineral oil is extremely sensitive. If the forearm is contaminated with machine oil, a short wash with soap and water will render the arm apparently clean; but when the arm is examined under the ultra-violet lamp, brilliant pin-points of fluorescence in the hair follicles betray the presence of unremoved oil. The intensity of this fluorescence gives a measure of the amount of oil remaining, and thus provides a means of comparing the efficiency of detergents.

\section{Standardized Oil Contamination}

Choice of Oils.-Some oils are more easily removed from the skin than others ; for example; a light spindle oil is more easily removed than a heavy gear oil. In general, the more viscous the oil, the more difficult its removal. By selecting three oils graded in this property for each experiment, differences in cleansers can be readily' appreciated. Thus a very efficient cleanser removes even heavy oils, whereas a poor cleanser removes only spindle oil. Further, by choosing several oils in general use, the results are made more widely applicable.' The oils chosen were :

1. Machine oil of viscosity 100 secs. BovertonRedwood at $140^{\circ} \mathrm{F}$.

2. Cutting oil of viscosity 50 secs. BovertonRedwood at $140^{\circ} \mathrm{F}$.

3. "Soluble" oil used without the addition of water.

Of these, machine oil was the most, and cutting oil the least difficult to remove, "soluble" oil being intermediate in this respect.

Site and Amount of Contamination.-The three oils were applied to corresponding, adjacent areas on the extensor aspect of each forearm, one drop of each oil being spread to cover a rectangle of constant dimensions. It is necessary to choose similar areas for the application of each oil as there are considerable differences in the nature of the skin of various parts of the hand and forearm. Such differences as the number and depth of the hair follicles and the degree of keratinization affect the result of the test.

The Use of Soap as a Standard of Comparison.-The arms having been contaminated identically, the right arm was washed in each experiment with the detergent under test, and the left with a stock 4 per cent. solution of white domestic soap. When examining the results, the left arm was used as a standard of comparison. It also afforded a check that the conclusion was not falsified by the introduction of some unexpected variable.

Other Factors affecting Detergency.-The efficiency of a detergent is affected by the amount of friction with which it is applied to the skin. In order to obtain light, 
even friction, a shaving brush was used to apply the detergents. The duration of washing was timed with a stop watch. Soft water at $40^{\circ} \mathrm{C}$. was used throughout the experiments. The tests were carried out on six subjects. There appeared to be a slight variability in the ease with which the oils could be removed from the skins of different individuals, but as the control wash with stock soap solution was carried out in each case, this factor did not affect the results.

Comparison of Washed Arms.-After washing, the amount of each oil remaining in the hair follicles was estimated by two methods :

(i) The hair follicles in four squares of $1 \mathrm{sq} . \mathrm{cm}$. were counted and recorded as fluorescing brightly, slightly, or not at all. Any great variation in these counts in any one oil-area after washing was due to the fact that washing has been uneven, and the experiment was repeated.

(ii) A permanent record of the fluorescence was obtained by photographing each stage of the experiment under standardized conditions. This enabled a clear comparison to be drawn between experiments performed at various times, but was not essential to the performance of the test.

\section{Details of TeChnique}

Light Source.-The source of ultra-violet light was a portable mercury vapour arc (current consumption $300 \mathrm{~W}$. at $200 \mathrm{~V}$.). It was screened with a filter of Wood's glass. To demonstrate the fluorescence the arm was held at a distance of approximately 12 inches from the lamp. A therapeutic ultra-violet lamp suitably. screened could alternatively be used.

Photographic Technique.-The camera position was standardized at a distance of 2 feet from the extensor surface of the forearm. Most of the photographs were taken on a Super XX film with an exposure of 35 to 45 secs. at F.11. A colourless gelatine filter was used to cut off the ultra-violet radiation reflected from the arm. Various filters, nominally the same, were tried, and showed considerable variation in their opacity to ultraviolet radiation. A process of trial and error was required to find a suitable filter.

Method.-Three rectangles of $15 \cdot 6 \cdot \mathrm{sq} . \mathrm{cm}$. were marked out on the corresponding areas of the extensor aspect of each forearm. One drop of each oil was spread with a glass rod to cover the appropriate rectangle and at this stage the arms were photographed (figs. 1 and 2 ).

The left arm was now washed for half a minute with the stock 4 per cent. soap solution. This was in the form of a loose gel which was suitable for application with a shaving brush. The right arm was washed for half a minute with the detergent under test. After washing, both arms were thoroughly rinsed, and dried by dabbing with a soft cloth. The arms were then compared and re-photographed (figs. 3 and 4).

The arms were given a further one-minue wash, then rinsed and dried as before. The final comparison was made and the arms photographed a third time (figs. 5 and 6).
TABLE 1

RELATIVE EFFICIENCY OF CLEANSING AGENTS IN REMOVING MINERAL OIL FROM THE SKIN

\begin{tabular}{|c|c|c|c|c|}
\hline \multicolumn{4}{|l|}{ Cleanser } & Grade \\
\hline \multicolumn{4}{|c|}{$2 \%$ Domestic soap solution ... } & V \\
\hline \multicolumn{4}{|c|}{$4 \%$ Domestic soap solution . . } & IV \\
\hline \multicolumn{4}{|c|}{$25 \%$ Sapo mollis B.P. solution } & III \\
\hline \multicolumn{2}{|c|}{$50 \%$ Sapo mollis B.P. solution } & . & & II \\
\hline \multicolumn{4}{|c|}{$\begin{array}{l}\left.\text { Soap powder } \begin{array}{lll} & \end{array}\right] \\
\text { Soap powder } 50 \%\end{array}$} & II \\
\hline \multicolumn{4}{|c|}{$\left.\begin{array}{lllll}\text { Woodflour } & 48 \% \\
\text { Borax } & 2 \%\end{array}\right\} \ldots$} & I \\
\hline \multicolumn{4}{|c|}{$\begin{array}{l}\text { Borax } 2 \% J \\
\text { Soap powder }\end{array}$} & $\left.\begin{array}{ll}\text { Soap powder } & 50 \% \\
\text { Woodflour } & 42 \%\end{array}\right\}$ \\
\hline \multicolumn{5}{|c|}{ 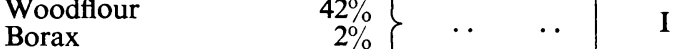 } \\
\hline \multicolumn{5}{|c|}{ Sodium pyrophosphate $6 \%$} \\
\hline \multicolumn{4}{|c|}{$\begin{array}{lll}\text { Ether soap B.P. } & \ldots & \ldots\end{array}$} & III \\
\hline \multicolumn{2}{|c|}{$\begin{array}{l}\text { Ether soap B.P. } \\
\text { Compound cleanser } \ddot{\ddot{A}}{ }^{*} \quad \cdots\end{array}$} & $\cdots$ & . & I \\
\hline \multicolumn{2}{|l|}{ Compound cleanser ' $\mathbf{B}$ ' $\dagger$} & & & I \\
\hline \multicolumn{2}{|c|}{ Triethanolamine alkyl sulphate } & & & IV \\
\hline \multicolumn{3}{|c|}{ Sodium secondary alkyl sulphate $\ldots$} & .. & IV \\
\hline \multicolumn{3}{|c|}{ Sodium oleyl p-anisidate sulphonate } & . & III \\
\hline \multicolumn{3}{|l|}{ Sulphonated castor oil } & . & III \\
\hline \multirow{2}{*}{\multicolumn{2}{|c|}{$\begin{array}{l}\text { Sulphonated oleate } \ldots \\
\text { Ethylene oxide condensate A }\end{array}$}} & & & II \\
\hline & & . & . & II \\
\hline \multicolumn{2}{|c|}{ Ethylene oxide condensate B } & & & V \\
\hline \multicolumn{4}{|c|}{ Ethylene oxide condensate C } & V \\
\hline \multicolumn{4}{|c|}{ Cetyl trimethyl ammonium bromide (crude) $1 \%$} & IV \\
\hline \multicolumn{4}{|c|}{ Cetyl pyridium bromide (crude) $1 \% \quad \ldots$} & IV \\
\hline
\end{tabular}

* Compound Cleanser ' $A$ ' is a mixture of soap and white spirit.

$\dagger$ Compound Cleanser ' $B$ ' is a mixture of mineral oil, white spirit, and sulphonated castor oil.

\section{RESULTS}

The results are shown in Table 1 . In this table five grades of efficiency are indicated. They express the degree of removal of the various oils from the hair follicles after one and a half minutes' washing. Their significance is as follows :

Grade I. Removed all three test oils.

II. Failed to remove machine oil only.

III. Removed cutting oil completely ; partly removed "soluble" oil and machine oil.

IV. Removed cutting oil completely ; considerable amounts of both "soluble" oil and machine oil remained in follicles.

V. Failed to remove all three oils.

The efficiency of soap in various concentrations was first investigated. A solution of less than 2 per cent. had negligible detergent properties when acting upon a surface heavily contaminated with oil. The 4 per cent. solution taken as the standard of comparison was reasonably efficient (Grade IV) and the efficiency increased with higher concentrations. To obtain 25 per cent. and 50 per cent. solutions of soap, 
the more soluble sapo mollis B.P. had to be used. This provided an imperfect" turbid "solution" which, however, remained fluid. Soap powder is the most concentrated form of soap possible. Used alone this was unsatisfactory from a practical point of view in that the addition of water caused clumping and caking of the particles.

Caking was avoided, and the detergent properties of the soap greatly improved by using a mixture containing equal parts of woodflour, and milled, dried soap powder. The woodflour was of such a consistency that when water was added to the mixture a smooth paste was formed. Washing with this paste was very efficient. It seems likely that the woodflour, in addition to preventing caking, acts as a mild scrubber and provides an alternative surface to which the oil may become attached. The inclusion of woodflour in a tablet soap is not recommended, as under these conditions the tablet becomes rough and abrasive.

Of the other cleansing agents examined, only those described as ' Compound Cleanser $\mathbf{A}$ ' and 'Compound Cleanser $B$ ' were much superior to soap. Both of these cleansers suffered from the defect that rinsing from the skin was difficult. Although the oil appeared to be loosened from the hair follicles, a fine fluorescent film was left behind on the skin after rinsing (fig. 7). Neither of these cleansers lathered to any extent, and it is possible that the increased surface area provided by a lather assists in keeping the oil in suspension. The absence of a lather also makes it difficult to see when rinsing is complete. The residual mixture of cleanser and oil can be removed by a second wash, preferably with soap and water.

The sulphonated oils tested, sulphonated castor oil and sulphonated oleate, were no more efficient than soap. The addition of an unsulphonated oil such as oleic acid, to the sulphonated oleate increased its power to loosen the test oils from the hair follicles, but reduced its rinsing properties. The addition of triethanolamine alkyl sulphate in the proportion of 2 per cent. to each of the sulphonated oils increased their efficiency-mainly by improving the stability of the final emulsion. However other considerations may make the use of a sulphonated oil advisable, for instance in the case of a worker whose skin has become damaged by exposure to an excess of alkali (Schwartz, 1941).

Of the other detergents examined, none was sufficiently superior to soap to justify its use on grounds of efficiency.

\section{Further Investigation of Selected Cleansers}

The three most efficient cleansers, namely soapwoodflour, 'Compound Cleanser A,' and 'Com- pound Cleanser B,' were now compared with each other using heavy gear oil (viscosity BovertonRedwood-1,000 secs. at $140^{\circ}$ F.) as the test oil. Experiments had previously demonstrated the difficulty of removing this oil from the skin.

Method.-One drop of the test oil was placed on each forearm and worked into the skin till it covered an area the size of a penny. Each arm was then washed with the shaving brush for one minute, the left with the soapwoodflour cleanser, the right with the 'Compound Cleanser A.' The arms were compared as before. The experiment was repeated comparing the soap-woodflour cleanser with the 'Compound Cleanser B.'

Result.-None of these cleansers removed all traces of the gear oil from the hair follicles. The soap-woodflour mixture showed a great advantage over the other two cleansers in that final rinsing from the skin was satisfactory. After the use of either of the 'Compound Cleansers,' a considerable amount of contaminating oil was deposited on the skin surrounding the original patch.

Alternative Method of Skin Cleansing.-It is the habit in some factories to clean the arms with a vegetable oil before washing with soap and water. Jones (1944) refers to the use of cotton-seed oil for this purpose. Experiments were performed in which the oil-contaminated arms were anointed with medicinal paraffin, and then washed by the standard technique. This method proved very efficient. Castor oil and oleic acid were similarly effective and it is likely that any bland oil of sufficiently low viscosity would be suitable for use in this way. This was the only method which removed the heavy gear oil completely from the hair follicles.

Practical Washing Trials.-Several washing trials of a more practical nature were carried out. In these trials the subjects washed their hands and forearms in the way to which they were accustomed. Only the duration of the wash was controlled. The results of these trials with the different cleansers corresponded closely with those of the standard experiments.

Observations made during these and previous experiments have shown that the efficiency of ordinary toilet soap varies greatly with the method of use. The best results were obtained by washing according to the following rules :

1. Do not wet the arms.

2. Using a minimum of water, work the soap from the tablet with the palms until a thick paste is formed.

3. Massage this paste into the skin.

4. Thin the resultant mixture of oil and soap by gradually adding water until a lather is formed.

5. Rinse thoroughly. 
It was proposed to extend trials of this nature to a group of workers in an automatic machine shop. These men become heavily contaminated with cutting oil. They were asked to report for examination during their working period and requested to refrain from washing before attending. Examined under the ultra-violet lamp, their arms showed the brilliant fluorescence of mineral oil. After they had washed, however, a considerable amount of fluorescent material remained on their arms. It appeared to be mainly in the hair follicles although not confined to these areas, and it could not be removed by oil-solvents such as acetone and xylol. Further examination of the material responsible for the fluorescence showed that it was keratin. Some of these small keratin aggregates were visible in ordinary light as comedoes. It is difficult to distinguish the fluorescence of these keratin "plugs" in the hair follicles from that of small amounts of mineral oil, and consequently a satisfactory washing trial in this group of workmen was impossible.

Comment.-It has been clearly shown that the removal of certain types of mineral oil from the skin is not easy. The removal of all but the most viscous oils can be accomplished by three of the cleansers examined, viz., soap-woodflour mixture and compound cleansers ' A' and 'B.' The soap-woodflour mixture was the most satisfactory in that final rinsing from the skin was easier.

By using a double procedure of washing first in a "thin" bland oil such as medicinal paraffin, and then washing with soap and water, even the most viscous oils could be removed.

The Removal of Skin Fat by Cleansing Agents. The use of powerful cleansing agents is attended by the danger of removing excessive amounts of natural fat from the skin. A few experiments were carried out to measure the amount of fat which might be removed in this way.

The amount of fat normally present on the surface of the skin was ascertained by immersing the hand and forearm in a cylinder of acetone for three minutes. The acetone was centrifuged to remove particulate matter and distilled. A residue of brown fat was obtained which amounted to about $60 \mathrm{mg}$. from one hand and forearm-representing a surface distribution of $0.06 \mathrm{mg}$. per sq.cm. Extraction of the fat from the skin in this way caused no ill effects beyond a slight dryness of the skin for an hour or so. In one subject mild " chapping" persisted for twenty-four hours. Repeated extraction of skin fat at varying intervals indicated that complete recovery might occur in four hours.

By extraction after washing with selected cleansers the amounts of fat removed by these agents could be obtained by difference. Thus washing for one minute with soap and water removed about one-fifth of the "extractable" fat, while washing for one minute with 'Compound Cleanser B,' which contained a fat solvent, removed nearly half of the "extractable" fat. The soap-woodflour cleanser also removed almost half of the " extractable" fat.

Thus the most efficient cleansers removed considerably more of the skin fat than did soap and water. As considerable variation in the fat replacement rate is likely, the frequent use of these cleansers by susceptible individuals may result in " chapping." In these individuals the use of an emollient cream after washing may be necessary to protect the skin until replacement of the natural fat has occurred.

\section{Evaluation of Barrier Creams}

The use of barrier creams is intended to lessen skin contamination and to make cleansing easier. Although the present investigation was concerned mainly with the oil-resisting properties of barrier creams, several creams which did not purport to be oil-resisting were also tested. In all, twenty-six creams were examined, including samples of most of the creams at present in use in industry. For descriptive purposes each of these creams was given a code letter.

The creams investigated were arranged in three groups according to their general composition. A finer classification appeared unnecessary in view of the lack of differentiation in efficiency which was demonstrated. The groups were as follows :

Group 1.-This group consisted of non-greasy creams, the basis of which was soap. Other oilinsoluble bases were sometimes included. The creams were "filled" with various inert powders. Their water content was relatively low.

Group II.-The creams in this group were mainly of the "vanishing" type designed to deposit either fats, soap, or cellulose bases in the hair follicles. Their water content was relatively high.

Group III.-This group consisted of creams made from various oily bases. Varying amounts of inert powder were included. Water was never present as a major constituent.

The oil-resisting properties of these creams were first compared. Further experiments were then performed on individual creams to ascertain their efficiency under varying conditions.

\section{Comparison of Barrier Creams}

The method was a modification of that used for the comparison of detergents, and the same general principles were maintained. Films of cream were applied to the extensor aspect of the forearm and 
TABLE 2

PENETRATION OF BARRIER CREAMS BY OIL (FIVE TO TEN MINUTES CONTACT TIME)

\begin{tabular}{|c|c|c|c|}
\hline Type & $\begin{array}{l}\text { Code } \\
\text { letter }\end{array}$ & Stated function & $\begin{array}{c}\text { Degree } \\
\text { of } \\
\text { penetration }\end{array}$ \\
\hline${ }^{\text {I }} \begin{array}{c}\text { (Soapy } \\
\text { base) }\end{array}$ & $\begin{array}{l}\text { A } \\
\text { B } \\
\text { C } \\
\text { D } \\
\text { E } \\
\text { F }\end{array}$ & $\begin{array}{c}\text { Oil-resisting } \\
,, \\
,, \\
\text { Oil and ', solvents }\end{array}$ & $\begin{array}{c}\text { Slight } \\
\text {," } \\
\text {," } \\
\text { Moderate } \\
\text {,, }\end{array}$ \\
\hline $\begin{array}{l}\text { II } \\
\text { (Vanishing } \\
\text { cream) }\end{array}$ & $\begin{array}{l}\mathbf{G} \\
\mathbf{H} \\
\mathbf{I} \\
\mathbf{J} \\
\mathbf{K} \\
\mathbf{L} \\
\mathbf{M} \\
\mathbf{N}\end{array}$ & $\begin{array}{c}\text { Oil- and water-resisting } \\
\text { Water-resisting } \\
\text { Dust and powders } \\
\text { Oil-resisting } \\
\text {,, } \\
:, \\
\text {," }\end{array}$ & $\begin{array}{c}\text { Moderate } \\
\text {," } \\
\text { ", } \\
\text { Gross } \\
\text { Moderate } \\
\text { ", } \\
\text { Gross }\end{array}$ \\
\hline $\begin{array}{l}\text { III } \\
\text { (Greasy } \\
\text { base) }\end{array}$ & $\begin{array}{l}\mathbf{O} \\
\mathbf{P} \\
\mathbf{Q} \\
\mathbf{R} \\
\mathbf{S} \\
\mathbf{T}\end{array}$ & $\begin{array}{c}\text { Water resisting } \\
\text { ", } \\
\text { ", } \\
\text {," }\end{array}$ & $\begin{array}{c}\text { Moderate } \\
\text {," } \\
, " \\
, \\
\text {," }\end{array}$ \\
\hline
\end{tabular}

contaminated with machine oil. Machine oil was chosen as it is of low enough viscosity to be fairly penetrating, and yet is difficult to remove from the skin once penetration has occurred. In each experiment a control contamination of normal skin was made. The arm was washed and dried in the standard method.

Method.-Three rectangles ( $15.6 \mathrm{sq} . \mathrm{cm}$.) were marked out on each forearm. Approximately the same amounts of four barrier creams were rubbed into each of the outer rectangles. The normal skin in the central areas was left untreated to provide controls. A thin film of machine oil was painted on all six rectangles (figs. 8 and 9). Each arm was then washed for one minute by the standardized method and the fluorescence in the different patches subsequently compared. Thus on each arm two creams were compared with each other and with a control of untreated skin (figs. 10 and 11).

Results.-The results are expressed in Table 2. The degree of penetration is assessed as "gross" where the fluorescence of the oil on the protected area is as great as on the control area ; " moderate" where the fluorescence is notably less, and "slight" where there is some evidence of oil in the hair follicles but the fluorescence is barely discernible.

It will be seen from Table 2 that only "slight" penetration of oil occurred through four of the creams of Type I. These " oil-resisting" creams (A, B, C, D) were definitely superior to all the others when tested as described. The two creams $(K, H)$ which allowed "gross" penetration were vanishing creams with a very high water content.

The greasy water-resisting creams of Group III appeared, somewhat surprisingly, to have exercised some protection of the skin. From the composition of these creams it seems more likely that this effect was due to the fact that they assisted in the removal of the oil, rather than that they prevented contamination of the skin. This point was elucidated in an experiment to be described later.

The general conclusions from this test were thus :

1. Certain creams of Type I might be of some value.

2. High water-content creams were unlikely to be of any value.

3. Fatty creams might assist in the removal of oil from the skin.

\section{Thickness of Creams}

In the previous experiment a liberal application of cream had been made. The effect of varying the thickness of the cream was now investigated. Creams A, B, C, and D were tested in this way, as they had already shown themselves the most promising.

It is not possible to measure accurately the thickness of a film of cream on the skin, but by rubbing in known weights of cream over equal areas the approximate thickness of the film may be calculated. This method is no doubt open to error due for instance to local variations in film thickness; but the variations are negligible in comparison with those occurring when the cream is used under practical conditions.

Method.-Three equal rectangles were marked on the

TABLE 3

PENETRATION OF OIL THROUGH FILMS OF VARYING THICKNESSES

\begin{tabular}{|c|c|c|c|c|}
\hline Film & $\begin{array}{l}\text { Weight } \\
\text { of } \\
\text { cream } \\
\text { per } \\
\text { rect- } \\
\text { angle } \\
\text { (g.) }\end{array}$ & $\begin{array}{c}\text { Esti- } \\
\text { mated } \\
\text { thick- } \\
\text { ness } \\
(\mu)\end{array}$ & $\begin{array}{l}\text { Degree } \\
\text { of } \\
\text { penetra- } \\
\text { tion }\end{array}$ & Appearance of film \\
\hline 1 & $0 \cdot 1$ & 64 & $\begin{array}{c}\text { Gross } \\
1\end{array}$ & $\begin{array}{l}\text { Thin transparent } \\
\text { layer ("invisible } \\
\text { glove") }\end{array}$ \\
\hline 2 & $0 \cdot 2$ & 120 & $\begin{array}{l}\text { Very } \\
\text { slight }\end{array}$ & $\begin{array}{l}\text { Distinctly visible } \\
\text { though practical to } \\
\text { wear }\end{array}$ \\
\hline 3 & $0 \cdot 3$ & 190 & Nil & Thick coating \\
\hline 4 & 0.4 & 250 & Nil & Even thicker coating \\
\hline
\end{tabular}




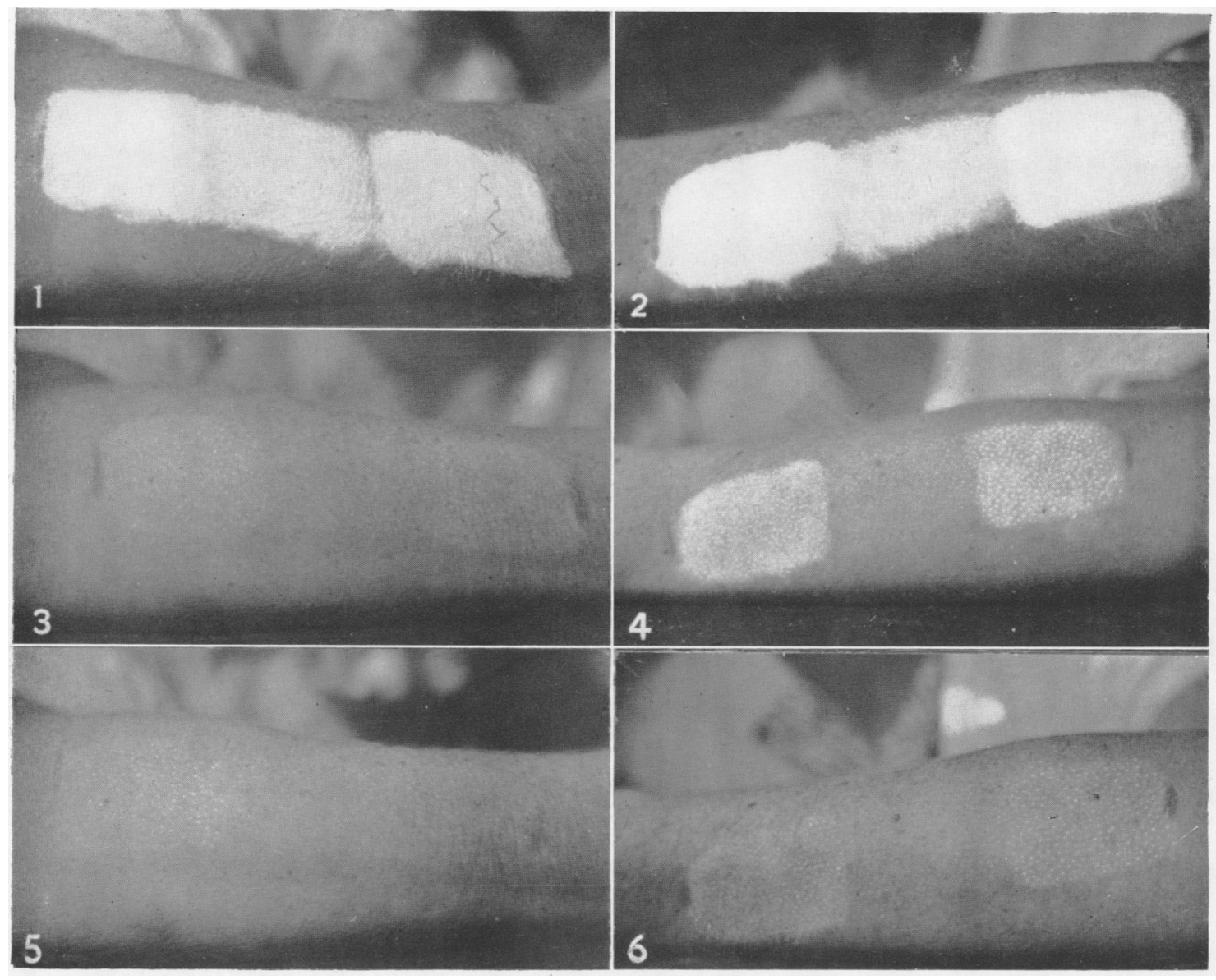

FIG. 1.-Machine oil, cutting oil, and soluble oil (left to right), applied to right forearm.

FIG. 3.-Right forearm after half a minute's wash with soap-woodflour cleanser.

Fig. 5.-Right forearm after a further one minute's wash with soap-woodflour cleanser.
FIG. 2.-Machine oil, cutting oil, and soluble oil (right to left), applied to left forearm.

FIG. 4.-Left forearm after half a minute's wash with four per cent. soap solution.

F!G. 6.-Left forearm after a further one minute's wash with 4 per cent. soap solution. 

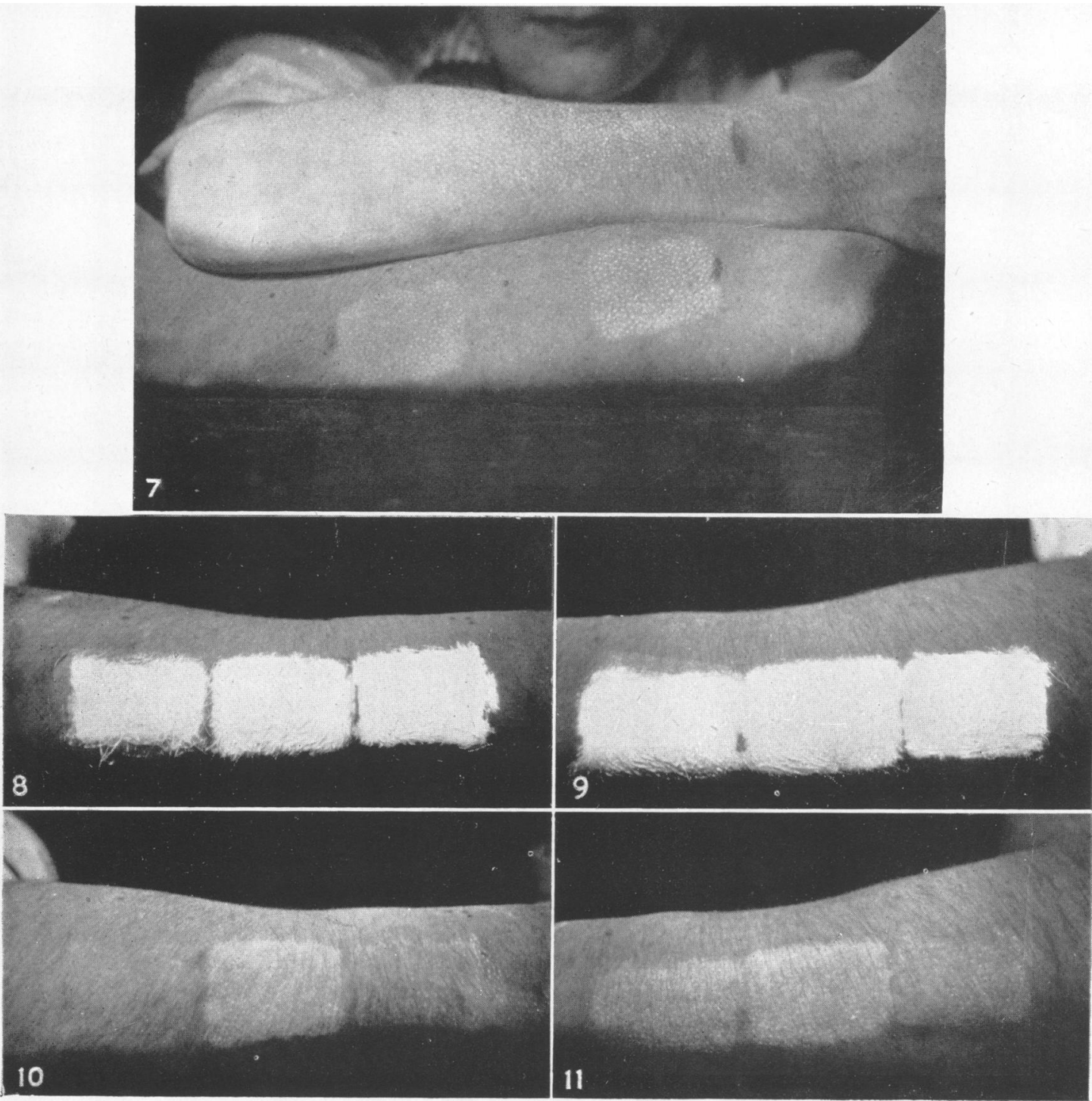

FIG. 7.-Comparison of arms washed for one and a half minutes with the "compound cleanser B" (right arm) and 4 per cent. soap solution (left arm). "Compound cleanser B" removes the oil more efficiently from the contaminated area. A considerable amount of oil is redeposited elsewhere, especially in the elbow region, where rinsing is difficult.

Fig. 8.-Film of machine oil covering (from left to right) cream $\mathbf{B}$, normal skin, and cream $\mathbf{J}$.

FIG. 10.-After washing for one minute. "Slight" penetration through cream B, "moderate" penetration through cream $\mathbf{J}$.
FIG. 9.-Film of machine oil covering (from left to right) cream $\mathrm{K}$, normal skin, and cream $\mathbf{J}$.

FIG. 11.-After washing for one minute. "Gross" penetration through cream K, "moderate" penetration through cream $\mathbf{J}$. 
extensor surface of each forearm ; $0 \cdot 1 \mathrm{~g}$., $0 \cdot 2 \mathrm{~g} ., 0.3 \mathrm{~g}$., and $0.4 \mathrm{~g}$. of cream $\mathrm{A}$ were rubbed into the outer rectangles. The central patches again acted as controls. A film of machine oil was painted over all six rectangles. The arms were immediately washed in the standard manner for one minute. The degrees of fluorescence in the areas were compared. The experiment was then repeated with creams $\mathrm{B}, \mathrm{C}$, and $\mathrm{D}$.

Results.-The results are expressed in Table 3.

There was no difference in the efficiency of the four creams tested. Each was totally inefficient in the thinnest film, but as the thickness of the cream was increased, improvement in efficiency occurred. Unfortunately, however, the films which were completely effective are too thick to be of practical value.

\section{Effect of Prolonged Contamination}

In the previous experiments the creams were exposed to mineral oil for a short period only (less than ten minutes). In the following series of tests the effects of increasing this exposure were demonstrated. The creams A, B, C, and D were subjected to this test. In addition a simple preparation consisting of 70 per cent. lanoline and 30 per cent. castor oil as an example of a greasy cream was tested in the same manner.

Method.-A film of cream was applied to the forearm. The film was approximately $120 \mu$ in thickness, that is, it corresponded to film 2 in the previous experiment (Table 3). Both the "protected" and the untreated skin were contaminated with a drop of machine oil. In a series of experiments the oil and cream were left in contact for varying periods up to one hour. During this time the subject carried out light laboratory duties with the sleeves rolled up. At the end of the period the arm was washed in the standard manner for one minute and the "protected" area compared with the control area.

Results.-The results are tabulated below in Table 4.

These results demonstrate the ineffectiveness of Creams $A, B, C$, and $D$ in resisting the penetration of mineral oil for more than a short period. The lanoline and castor-oil cream showed no such loss of efficiency with time. In vitro tests with coated filter paper show that the lanoline cream is much more readily penetrated by mineral oil than the soapy creams. It must therefore be concluded that the observed effect is due to the fact that it facilitates the removal of the oil, rather than prevents physical contact with the skin.

\section{Comment}

The results of these experiments indicate that the soapy barrier cream designed to resist oil penetra-
TABLE 4

EFFECT OF INCREASING EXPOSURE TIME OF CREAMS TO MACHINE OIL

\begin{tabular}{c|c|c|c|c|c}
\hline & \multicolumn{3}{|c|}{ Residual fluorescence after washing } \\
\cline { 2 - 5 } Cream & $\begin{array}{c}\text { Imme- } \\
\text { diate } \\
\text { removal }\end{array}$ & $\begin{array}{c}\text { After } \\
\frac{1}{4} \text { hour }\end{array}$ & $\begin{array}{c}\text { After } \\
\frac{1}{2} \text { hour }\end{array}$ & $\begin{array}{c}\text { After } \\
\frac{3}{4} \text { hour }\end{array}$ & $\begin{array}{c}\text { After } \\
1 \text { hour }\end{array}$ \\
\hline A & nil & V. slight & Mod. & Gross & Gross \\
B &,, &, &, &, &, \\
C &, &, &, &, &, \\
D &,, &,, &, &, & ", \\
$\begin{array}{c}\text { Lanoline } \\
\text { oil castor }\end{array}$ & V. slight & , & V. slight & V. slight & V. slight \\
\hline
\end{tabular}

tion, although effective for short periods such as half an hour, permits complete penetration of oil when the duration of the contamination is of one hour or more. In these experiments, much thicker films were used than are generally recommended. Where thinner films were used $(64 \mu)$ the soapy creams were totally ineffective-even this thickness being much greater than the $30 \mu$ often advocated. The liquid vanishing creams were valueless.

The greasy creams, although incapable of functioning as " barriers," appeared to assist in the removal of oil.

\section{Discussion}

It is not claimed that an exhaustive examination of cleansing agents and protective creams has been made. The aim has been to evolve a method by which such compounds can be evaluated by the medical officer in industry. Nevertheless the investigation has yielded useful information concerning the problem of skin contamination by mineral oil. Data obtained from laboratory experiments such as these cannot be regarded as conclusive. The final judgment must be based upon the results of a user trial. The difficulties of conducting satisfactorily controlled user trials are unfortunately very great. However, it appears unlikely that any compound which failed to satisfy the criteria of the tests described would be of much value in practice. The converse is obviously not true-an agent which satisfies the laboratory tests may still fail under practical conditions. This is true of protective creams in particular. In these experiments no account has been taken of such factors as visible perspiration which occurs when heavy manual labour is done; nor have the creams been tested with regard to their ability to stand up 
to the friction ordinarily encountered during work from clothing and other agents.

As judged by our experiments the value of barrier creams to those exposed to gross oil contamination would appear to be low. A film which would be practical to wear fails to prevent penetration of oil into the hair follicles if the duration of the contamination is greater than one hour. Once penetration has occurred the soapy " oil-resisting" cream does not appear to assist in the removal of the oil. The greasy cream, although it rapidly becomes mixed with the contaminating oil on the skin, assists in subsequent cleansing. As a result of clinical observation and animal experiments, Twort (1934) suggested the use of a mixture of lanoline and olive oil as a protective application for oil workers. It is possible that the use of a cream of this type may be of benefit in two ways-diluting the contaminating oil on the skin and assisting subsequent cleansing. It is accordingly suggested that where, by reason of popular demand, a protective cream for oil workers is required, it should be of a fatty nature. It must be recognized, however, that the use of such a preparation cannot be regarded as affording a great deal of protection, and it must not distract attention from other and more valuable means of preventing oil contamination, such as the use of protective clothing, the provision of adequate washing and laundry facilities, and other measures of general hygiene.

Since reliance cannot be placed upon protective applications, it becomes more important to achieve the satisfactory removal of oil from the hair follicles after work. These experiments have shown that this is not a simple problem, and that particular care must be exercised in washing. \The tests have defined certain agents which are likely to be of value ; of these the most efficient was a mixture of soap powder and woodflour. The woodflour used in this cleansing mixture should be fine enough to pass a 40 mesh and it should not be derived from any wood which is likely to possess sensitizing properties. The soap powder should contain a minimum of free alkali.

The use of powerful cleansing agents is accompanied by the risk of removing too much of the natural skin fat. Although in most people this risk is not likely to be great in view of the rapid replacement of fat lost from the skin, the continued use of such agents by certain individuals may result in excessive dryness of the skin and chapping in dry weather. This may be avoided by the use of an emollient cream after work in order to compensate for any fat loss.

The alternative method of a preliminary wash in thin bland oil before using soap and water has been shown to be efficient and to cause minimal skin trauma ; it has the disadvantage of being a double procedure but should not be difficult to put into practice as workmen are all too keen to use kerosene or other solvents before washing.

It has thus been shown that the prevention of skin contamination by mineral oil is not easy. There is no doubt that directly or indirectly mineral oils cause a considerable proportion of industrial skin disease. Elimination of this group of skin diseases is only likely to be achieved by improving the design of machinery to reduce the risk of contamination or possibly by the substitution of oils which are non-irritating to the skin. That the use of protective creams or powerful cleansing agents is considered, must be a reflection upon our standards of engineering efficiency.

\section{Summary}

1. A method is described of assessing the value of cleansing agents and protective creams to workmen exposed to mineral oils. The method is based on the detection in ultra-violet light of oil persisting in the hair follicles after the use of these agents.

2. A number of cleansing agents have been examined. Of these a mixture of equal parts of milled, dried soap-powder, and fine woodflour gave the most satisfactory results.

3. A range of proprietary barrier creams has been examined. None of these gave satisfactory protection of the skin.

4. The excessive removal of fat from the skin is discussed, and a method of investigating this problem is described. I wish to thank those manufacturers of cleansing agents and
barrier creams who so kindly supplied me with samples of their products. Their co-operation and advice has been of considerable help.

For much helpful criticism and advice I am indebted to Dr. J. R. Squire, Director of the Medical Research Council Industrial Medicine Research Unit, Birmingham Accident Hcspital, at whose suggestion this investigation was carried out,

\section{REFERENCES}

Schwartz, L. (1941). Publ. Hlth. Rep., Wash., 56, 1790.

Jones, A. Thelwall (1944). Brit. J. industr. Med., 3, 83. Twort, C. C., and J. M. (1934). Lancet, 1, 286. 